\title{
Keberlanjutan Dimensi Ekonomi, Teknologi Infrastruktur, dan Hukum Kelembagaan untuk Evaluasi Pengembangan Kuda Sandelwood di Kabupaten Sumba Barat Daya
}

\section{Sustainability of Economy, Infrastructure Technology, and Institution Law Dimensions to Evaluate Sandelwood Horse Development in Regency of South-West Sumba}

\author{
M. D. S. Randu ${ }^{1}$ dan B. Hartono ${ }^{2}$ \\ ${ }^{1}$ Jurusan Peternakan, Politeknik Pertanian Negeri Kupang \\ ${ }^{2}$ Fakultas Peternakan, Universitas Brawijaya Malang \\ Corresponding Author:deddy_randu@yahoo.co.id
}

\begin{abstract}
Sandelwood horse is a genetic resource of Indonesia local horse developed and has strategic roles in the Regency of South-West Sumba. Nowadays, the existing condition of the horse development shows problems deal with demand, use, and management on farmer's level. If the condition is not care urgently, it will influence the sustainability. Research objectives were to analyze: 1) index and sustainability status of sandalwood horse development in the Regency of South-West Sumba based on a review of economy, infrastructure-technology, and institution-law dimensions, and 2) sensitive attributes influenced the horse development in the research site. The research applied analysis method of Multi-Dimensional Scaling (MDS) called Rap-horse and its result is stated in form of index and sustainability status. Analysis of Leverage and Monte Carlo were used to evaluate sensitive factors influencing the index and sustainability status including error influence in the Rap-horse analysis. The result showed that the index of economy dimension was $33.08 \%$, infrastructure-technology was $39.40 \%$, and institution-law was $36.28 \%$, meaning the horse existed on unsustainability status. Based on 29 attributes analyzed, there were 13 sensitive attributes influencing the index and sustainability status with a low error level at $95 \%$ significant level. The development of sandalwood horse sustainability can be optimized by improving the dimensions comprehensively those four attributes of economy, three attributes of infrastructuretechnology, and six attributes of institution-law.
\end{abstract}

Key words: genetic resources, Sandalwood horse, South-West Sumba, sustainability.

\begin{abstract}
ABSTRAK
Kuda Sandelwood merupakan sumberdaya genetik rumpun kuda lokal Indonesia yang dikembangkan dan memiliki peran strategis di Kabupaten Sumba Barat Daya. Kondisi faktual pengembangan kuda Sandelwood saat ini menunjukkan permasalahan berkaitan permintaan, pemanfaatan, dan manajemen di tingkat peternak. Kondisi tersebut apabila tidak ditangani dikhawatirkan mempengaruhi dari sisi keberlanjutan. Penelitian bertujuan menganalisis(1) indeks dan status keberlanjutan pengembangan kuda Sandelwood di Kabupaten Sumba Barat Daya berdasarkan tinjauan dimensi ekonomi, teknologi-infrastruktur, dan hukum-kelembagaan, serta(2) atribut sensitif yang mempengaruhi keberlanjutan pengembangan kuda Sandelwood di Kabupaten Sumba Barat Daya. Penelitian menggunakan metode analisis Multi Dimensional Scalling (MDS) yang disebut Rap-horse dan hasilnya dinyatakan dalam bentuk indeks maupun status keberlanjutan. Analisis Leverage dan Monte Carlo digunakan untuk mengetahui faktor sensitif yang mempengaruhi indeks dan status keberlanjutan maupun pengaruh galat dalam analisis Rap-horse. Hasil analisis menunjukkan bahwa indeks dimensi ekonomi $(33,08 \%)$, teknologi-infrastruktur $(39,40 \%)$, dan hukum-kelembagaan $(36,28 \%)$ berada pada status kurang berkelanjutan. Dari 29 atribut yang dianalisis, 13 atribut sensitif berpengaruh terhadap peningkatan indeks maupun status keberlanjutan dengan tingkat kesalahan yang rendah pada taraf kepercayaan 95\%. Untuk mengoptimalkan pengembangan kuda Sandelwood yang berkelanjutan, perlu dilakukan perbaikan menyeluruh terhadap 4 atribut dimensi ekonomi, 3 atribut dimensi teknologi-infrastruktur, dan 6 atribut dimensi hukumkelembagaan.
\end{abstract}

Kata kunci: sumber daya genetik, kuda Sandelwood, Sumba Barat Daya, keberlanjutan 


\section{PENDAHULUAN}

Kuda merupakan komoditas ternak yang penyebarannya di dunia kurang merata apabila dibandingkan dengan ternak sapi,domba, kambing, babi, dan unggas, sehingga dikategorikan sebagai sumberdaya genetik yang beresiko (Olsen, 2006; Vila et al, 2006). Ternak kuda yang dikembangkan di Indonesia pada tahun 2016 memiliki penyebaran yang bervariasi, dengan populasi tertinggi berada di tiga provinsi, yaitu: Sulawesi Selatan (190.281ekor), Nusa Tenggara Timur (116.843 ekor), dan Nusa Tenggara Barat (65.099 ekor). Ternak kuda di Provinsi Nusa Tenggara Timur memberikan kontribusi sebesar 26,69\% terhadap total populasi secara nasional (Ditjennak Kementan, 2016).

Sumba Barat Daya merupakan salah satu kabupaten yang terletak di Pulau Sumba Provinsi Nusa Tenggara Timur, dan memiliki potensi pengembangan ternak kuda. Hal tersebut selaras dengan keputusan Menteri Pertanian Republik Indonesia nomor 426/Kpts/SR.120/3/2014 yang menetapkan kuda Sandelwood sebagai sumberdaya genetik (SDG) rumpun kuda lokal Indonesia dengan sebaran asli geografis berada di wilayah Pulau Sumba (Ditjen PKH Kementan, 2014). Potensi lainnya adalah kemampuan adaptasi pada kondisi klimatik wilayah setempat, padang rumput seluas \pm 17.607 Ha sebagai sumber pakan kuda, adanya dukungan pemerintah daerah, tradisi beternak kuda yang telah dilakukan secara turun-temurun, ketersediaan lembaga modal, pasar hewan, tingginya permintaan dan harga jual,dukungan transportasi laut maupun udara, serta pemanfaatan yang sangat dominan dalam berbagai kegiatan sosial budaya (Randu, 2018). Kuda Sandelwood di Kabupaten Sumba Barat Daya berperan penting meningkatkan ekonomi peternak sekaligus melestarikan kearifan budaya lokal. Kuda Sandelwood merupakan komoditas ternak yang wajib digunakan pada setiap aktivitas kebudayaan seperti dalam upacara perkawinan, kematian, maupun ritual pasola. Ritual pasola merupakan tradisi saling melempar lembing dari atas kuda yang sedang dipacu dan merupakan destinasi pariwisata yang diunggulkan di Kabupaten Sumba Barat Daya.

Kuda

Sandelwood

yang

dikembangkan di Kabupaten Sumba Barat Daya saat ini mengalami kesenjangan antara pengeluaran antar pulau yang meningkat $57,81 \%$ selama tahun 2011-2015, dibandingkan jumlah populasi yang menurun 2,75\% setiap tahunnya (Dinas Peternakan Kabupaten SBD, 2016). Aktivitas pemeliharaan kuda Sandelwood di tingkat peternak masih dilakukan secara tradisional dan mengikuti kebiasaan yang diwariskan secara turun-temurun walaupun tetap memiliki tingkat pemanfaatan yang tinggi terutama untuk aktivitas kebudayaan maupun ekonomi. Pemerintah Kabupaten Sumba Barat Daya juga terus mendorong kebijakan pembangunan dalam bidang peternak dalam upaya mewujudkan sub sektor peternakan yang berkelanjutan, mandiri, berdaya saing, serta tangguh dengan mendasarkan kepada pemanfaatan sumberdaya lokal untuk peningkatan kesejahteraan masyarakat, pelestarian lingkungan, danpeningkatan ekonomi daerah. Erhun (2015), Sutanto dan Hendraningsih (2011) menyatakan bahwa pembangunan berkelanjutan harus ditujukan untuk memenuhi kebutuhan saat ini dan masa mendatang melalui pemanfaatan, pemeliharaan, dan konservasi sumberdaya alam dengan berorientasi kepada perubahan ekonomi, teknologi, maupun kelembagaan sehingga menjamin terpenuhinya kebutuhan manusia.

Kondisi faktual menunjukkan tingginya peranan ternak kuda dalam kehidupan masyarakat saat ini tidak diimbangi tersedianya populasi dan manajemen yang memadai di tingkat peternak. Oleh karena itu, solusi yang perlu diterapkan adalah menerapkan konsep pengembangan kuda Sandelwood yang berkelanjutan (sustainable Sandlewood equine development) di Kabupaten Sumba Barat Daya. Konsepsi tersebut tidak sematamata hanya mengintegrasikan pendekatan dimensi ekologi maupun sosial budaya, namun juga hendaknya 
mempertautkandimensi ekonomi, teknologiinfrastruktur dan hukum-kelembagaan. Penelitian bertujuan untuk mengevaluasi keberlanjutan pengembangan kuda Sandelwood berdasarkan tinjauan dimensi ekonomi, teknologi-infrastruktur, dan hukum-kelembagaan. Manfaat hasil penelitian ini sekiranya dijadikan acuan dalam membuat kebijakan pengembangan kuda Sandelwood yang berkelanjutan di Kabupaten Sumba Barat Daya.

\section{MATERI DAN METODE}

Penelitian dilakukan bulan Maret September 2017 di Desa Pero Batang dan Desa Ate Dalo (Kecamatan Kodi), Desa Waikaninyo dan Desa Umbu Ngedo (Kecamatan Kodi Bangedo), Desa Waiha dan Desa Wainyapu (Kecamatan Kodi Balaghar), Kabupaten Sumba Barat Daya. Lokasi Penelitian ditetapkan dengan mempertimbangkan posisi strategis sebagai gerbang perdagangan maupun pariwisata di Kabupaten Sumba Barat Daya, representasi wilayah dengan jumlah populasi kuda Sandelwood yang rendah namun dominan dimanfaatkan untuk aktivitas ekonomi, serta merupakan satu-satunya wilayah di Kabupaten Sumba Barat Daya yang menyelenggarakan ritual pasola menggunakan kuda Sandelwood.

\section{Jenis dan Sumber Data}

Jenis data yang digunakan dalam penelitian meliputi data primer dan sekunder. Data primer diperoleh secara langsung dari 80 orang peternak kuda Sandelwood yang ditetapkan dengan mempertimbangkan pengalaman memelihara kuda Sandelwood minimal3(tiga) tahun terakhir, terlibat dalam kegiatan pasola minimal 2 (dua) tahun terakhir, pernah menjual kuda Sandelwood minimal 1 (satu) tahun terakhir, serta memiliki motivasi yang kuat untuk mengembangkan kuda Sandelwood. Pengumpulan data primer dilakukan menggunakan teknik survei maupun observasi lapangan, dengan berpedoman pada daftar pertanyaan yang berkaitan dengan 8 atribut dimensi ekonomi, 10 atribut dimensi teknologi-infrastruktur, dan 11 atribut dimensi hukum- kelembagaan. Data sekunder diperoleh dari berbagai sumber dan instansi terkait melalui koleksi dokumen tertulis diantaranya berasal dari Badan Pusat Statistik, Badan Perencanaan, Penelitian dan Pengembangan Daerah, Dinas Peternakan, maupun dokumen dari instansi lainnya di Kabupaten Sumba Barat Daya yang memiliki relevansi dengan tujuan penelitian.

\section{Metode Analisis Data}

Pengembangan kuda Sandelwood di Kabupaten Sumba Barat Daya yang berkelanjutan dianalisis menggunakan Multi Dimensional Scalling (MDS) dengan teknik pendekatan Rap-horse (Rapid Appraisal for horse), diadopsi dan dikembangkan dari metode Rapfish untuk menilai status keberlanjutan perikanan tangkap (Kavanagh, 2001; Pitcher and Preikshot, 2001; Kavanagh and Pitcher, 2004). Analisis Leverage digunakan untuk menentukan berbagai atribut dimensi ekonomi, teknologiinfrastruktur, dan hukum-kelembagaan yang sensitif mempengaruhi keberlanjutan pengembangan kuda Sandelwood. Analisis Monte Carlo digunakan untuk mengevaluasi pengaruh kesalahan atribut pada taraf kepercayaan 95\% (Isyanto dan Dehen, 2015).

\section{Tahapan Analisis Data}

Beberapa tahapan analisis data penelitian sebagaimana dikemukakan Kavanagh (2001); Pitcher and Preikshot (2001); Kavanagh and Pitcher (2004); Isyanto dan Dehen (2015); Hasdi et al. (2015), sebagai berikut:

1. Menentukan atribut untuk dimensi ekonomi, teknologi-infrastruktur, dan hukum-kelembagaan.

2. Melakukan penilaian atribut dimensi ekonomi, teknologi- infrastruktur, dan hukum-kelembagaan pada skala ordinal 0 (buruk) sampai 3 (baik) berdasarkan kriteria keberlanjutan setiap dimensi.

3. Melakukan perhitungan indeks dan status keberlanjutan dimensi ekonomi, teknologi-infrastruktur, dan hukumkelembagaan menggunakan software 
Rapfish Versi 3.1. Indeks dan status keberlanjutan dapat dilihat pada Tabel 1.

Tabel 1. Indeks dan status keberlanjutan pengembangan kuda Sandelwood berdasarkan hasil analisis Rap-horse

\begin{tabular}{cc}
\hline Indeks & Kategori Status \\
\hline $0,00-25,00$ & Buruk (Tidak berkelanjutan) \\
$25,01-50,00$ & Kurang (Kurang berkelanjutan) \\
$50,01-75,00$ & Cukup (Cukup berkelanjutan) \\
$75,01-100,00$ & Baik (Sangat berkelanjutan) \\
\hline
\end{tabular}

4. Melakukan analisis leverage terhadap masing-masing atribut dimensi ekonomi, teknologi-infrastruktur, dan hukumkelembagaan yang sensitif mempengaruhi keberlanjutan. Atribut sensitif ditentukan berdasarkan urutan prioritas hasil analisis dengan melihat perubahan ordinasi Root Mean Square (RMS) pada sumbu x. Semakin tinggi nilai RMS pada setiap atribut menunjukkan pengaruh atribut yang besar dalam mempengaruhi status keberlanjutan.

5. Melakukan analisis Monte Carlo untuk memperhitungkan aspek ketidakpastian atau pengaruh galat yang diakibatkan oleh proses penilaian, perhitungan, maupun analisis pada taraf kepercayaan $95 \%$. Apabila perbedaan (selisih) nilai perhitungan antara indeks keberlanjutan MDS dengan indeks keberlanjutan Monte Carlo kurang dari 1 menunjukkan rendahnya tingkat kesalahan di dalam melakukan analisis.

6. Melakukan perhitungan nilai stress dan koefisien determinasi untuk mengetahui tingkat keakuratan analisis MDS. Model yang akurat ditunjukkan melalui nilai stress $\leq 0,25 \quad(25 \%)$ dan koefisien determinasi $\geq 1(100 \%)$.

\section{HASIL DAN PEMBAHASAN}

\section{Evaluasi Keberlanjutan Pengembangan Kuda Sandelwood}

Dalam penelitian evaluasi pengembangan kuda Sandelwood di Kabupaten Sumba Barat Daya, penentuan indeks dan status keberlanjutan dilakukan untuk dimensi ekonomi, teknologiinfrastruktur, dan hukum- kelembagaan. Secara implementatif, penilaian indeks keberlanjutan dilakukan terhadap 29 atribut oleh 80 orang responden yang tersebar di dalam enam desa dalam wilayah Kecamatan Kodi, Kodi Bangedo, dan Kodi Balaghar. Hasil analisis indeks keberlanjutan pengembangan kuda Sandelwood di Kabupaten Sumba Barat Daya menggunakan Multi Dimensional Scalling (MDS) dengan pendekatan Rap-horse dapat dilihat pada Gambar 2, 3, 4, dan 5.

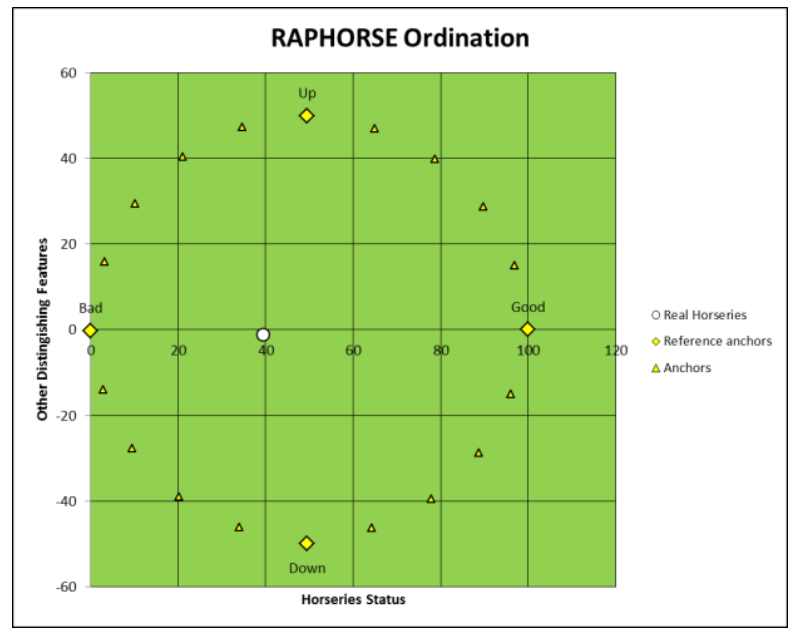

Gambar 2. Indeks keberlanjutan dimensi ekonomi

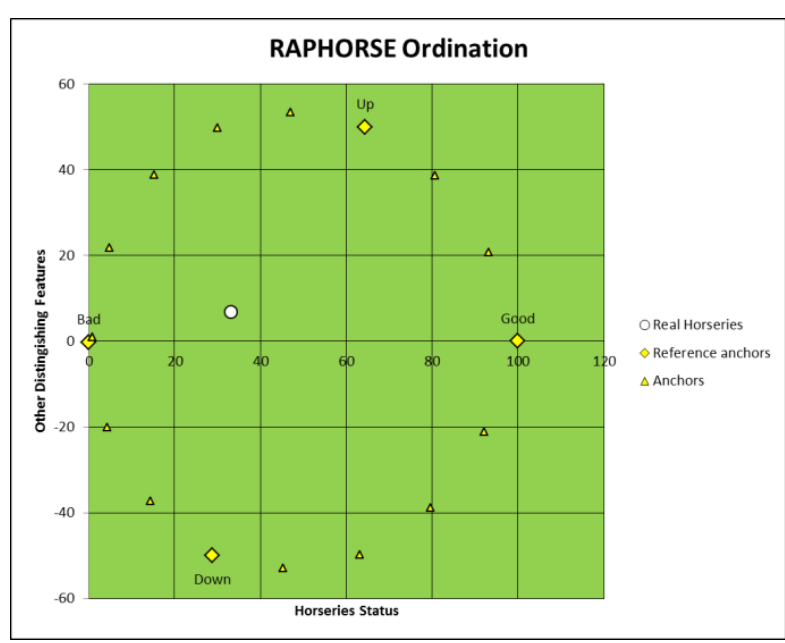

Gambar 3. Indeks keberlanjutan dimensi teknologi-infrastruktur 


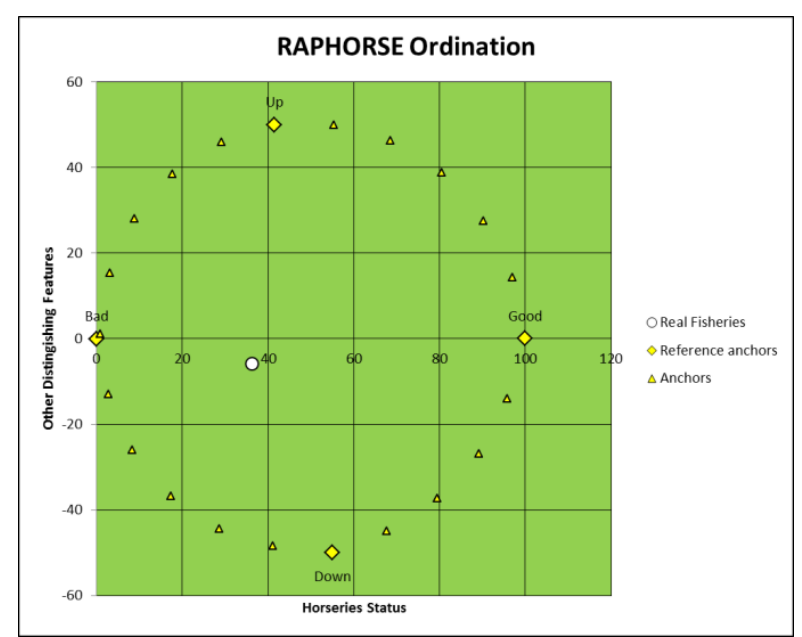

Gambar 4. Indeks keberlanjutan dimensi hukumkelembagaan

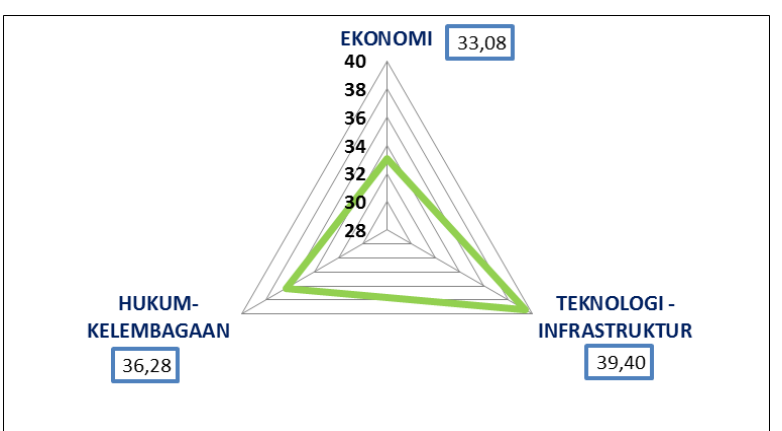

Gambar 5. Diagram layang indeks keberlanjutan pengembangan kuda Sandelwood di Kabupaten Sumba Barat Daya

Berdasarkan Gambar 2, 3, dan 4 diketahui indeks dimensi ekonomi adalah $33,08 \%$, teknologi-infrastruktur adalah $39,40 \%$, dan hukum-kelembagaan adalah $36,28 \%$ sehingga ketiga dimensi tersebut digolongkan ke dalam status kurang berkelanjutan. Kondisi tersebut mencerminkan pengembangan kuda Sandelwood di Kabupaten Sumba Barat Daya kurang mendapatkan dukungan dimensi ekonomi, teknologi-infrastruktur, dan hukum-kelembagaan akibat dipengaruhi oleh beberapa atribut yang memberikan pengaruh terbesar. Suyitman et al. (2012) menyatakan bahwa indeks keberlanjutan yang berkisar antara 26\% - 50\% berada dalam kategori status kurang berkelanjutan.

Berdasarkan Gambar 5. diketahui bahwa Indeks masing-masing dimensi walaupun memiliki perbedaan nilai namun secara proporsional saling berinteraksi satu sama lain. Dengan demikian perubahan yang terjadi pada satu dimensi secara langsung maupun tidak langsung akan mempengaruhi perubahan pada dimensi lainnya. Syarifuddin (2009) menyatakan bahwa konsep pembangunan berkelanjutan bukan mengindikasikan semua nilai indeks yang sama besar namun mengupayakan agar setiap dimensi berada pada kategori status keberlanjutan yang cukup atau baik. Upaya Peningkatan indeks keberlanjutan pengembangan kuda Sandelwood di Kabupaten Sumba Barat Daya pada masa mendatang dapat dilakukan melalui perbaikan terhadap berbagai atributsensitif dari dimensi ekonomi, teknologiinfrastruktur, dan hukum-kelembagaan.

\section{Analisis Leverage Pengembangan Kuda Sandelwood}

Analisis leverage digunakan untuk mengetahui atribut-atribut sensitif yang mempengaruhi indeks keberlanjutan pengembangan kuda Sandelwood di Kabupaten Sumba Barat Daya. Berdasarkan hasil analisis diketahui terdapat 13 atribut sensitif dari 29 atribut yang dinilai oleh responden. Hasil analisis leverage terhadap dimensi ekonomi, teknologi-infrastruktur, dan hukum-kelembagaan dapat dilihat pada Tabel 2 dan Gambar 6, 7, 8.

Tabel 2. Atribut sensitif yang berpengaruh terhadap pengembangan kuda Sandelwood

\begin{tabular}{ll}
\hline No & Uraian \\
\hline & Dimensi Ekonomi (4 Atribut) \\
1 & Ketersediaan Industri Pengolahan Hasil \\
2 & Mekanisme Penjualan Kuda Sandelwood \\
3 & Ketersediaan Informasi Harga Komoditas \\
4 & Modal Usaha Kuda Sandelwood \\
& Dimensi Teknologi-Infrastruktur (3 Atribut) \\
5 & Ketersediaan Poskeswan \\
6 & Ketersediaan Sarana Transportasi \\
7 & Penerapan Teknologi Pengolahan Hasil \\
& Dimensi Hukum-Kelembagaan(6 Atribut) \\
8 & Pusat Pelatihan \& Konsultasi Kuda Sandelwood \\
9 & Ketersediaan Tenaga Penyuluh \\
10 & Kejadian Pencurian Kuda Sandelwood \\
11 & Kerjasama Pemasaran Kuda Sandelwood \\
12 & Kebijakan Anggaran Peng Kuda Sandelwood \\
13 & Frekuensi Penyuluhan
\end{tabular}



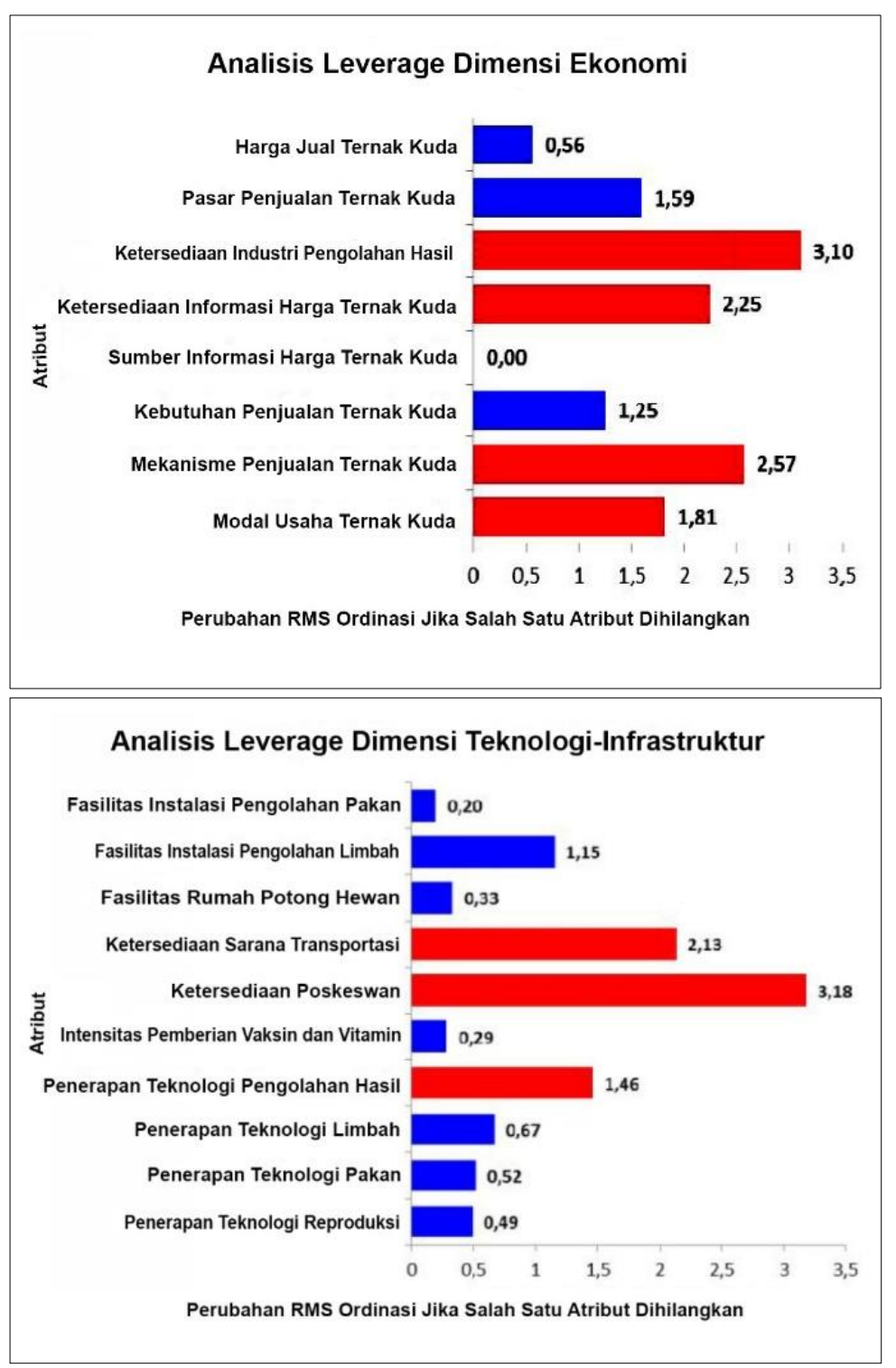

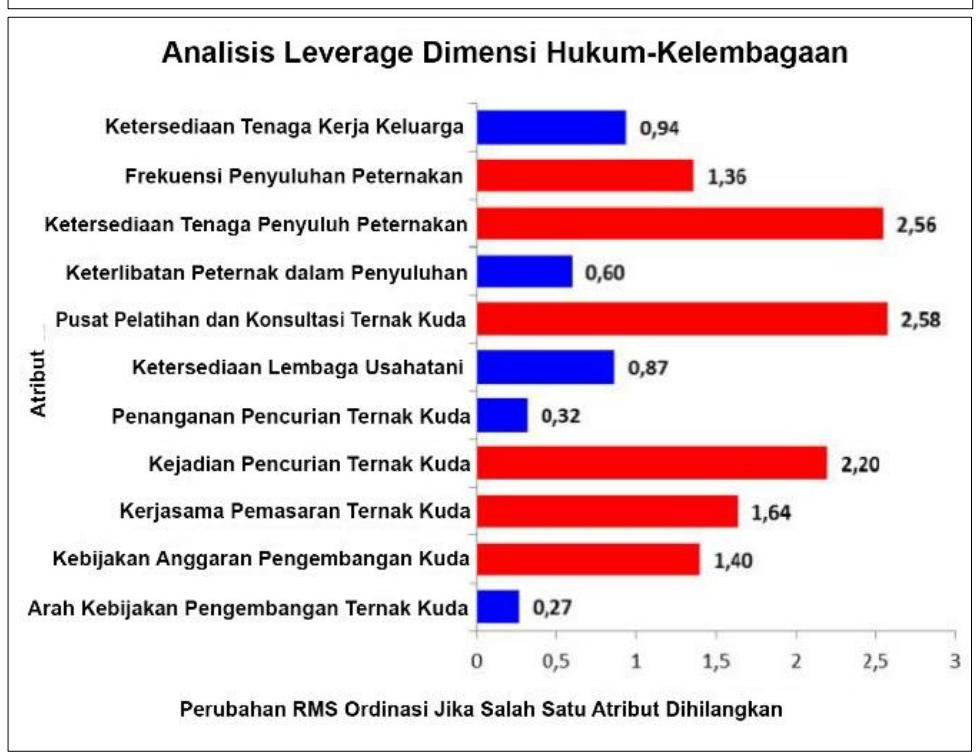

Gambar 6. Atribut sensitif yang mempengaruhi keberlanjutan dimensi ekonomi

Gambar 7. Atribut sensitif yang mempengaruhi keberlanjutan dimensi teknologi-infrastruktur
Gambar 8. Atribut sensitif yang mempengaruhi keberlanjutan dimensi hukum-kelembagaan 
Berdasarkan Tabel 2 dan Gambar 6, 7, 8, diketahui bahwa peningkatan indeks keberlanjutan dimensi ekonomi dapat dilakukan melalui perbaikan terhadap empat atribut sensitif dalam pengembangan kuda Sandelwood di Kabupaten Sumba Barat Daya. Hal tersebut disebabkan karena ketersediaan industri pengolahan hasil ternak kuda seperti: pengolahan daging, susu, pupuk, dan kulit belum dikembangkan saat ini. Pada sisi yang lain, mekanisme penjualan kuda Sandelwood di tingkat peternak umumnya hanya dilakukan melalui para pedagang perantara (pengumpul) dengan selisih harga yang cukup besar akibat terbatasnya informasi harga komoditas di tingkat peternak. Upaya peternak untuk mengembangkan kuda Sandelwood juga dibatasi oleh ketersediaan modal yang dimiliki. Kondisi tersebut pada akhirnya turut mempengaruhi keberlanjutan dimensi ekonomi karena berkaitan dengan ketidakmampuan peternak dalam mempengaruhi harga maupun meningkatkan jumlah kepemilikan kuda Sandelwood.

Perbaikan tiga atribut sensitif pada dimensi teknologi- infrastruktur dalam pengembangan kuda Sandelwood juga dapat dilakukan melalui peningkatan jumlah dan optimalisasi fungsi poskeswan sebagai ujung tombak pelayanan kesehatan ternak untuk mengatasi kejadian penyakit terutama Surra yang menjadi penyakit endemik di Kabupaten Sumba Barat Daya. Disamping peningkatan ketersediaan sarana transportasi untuk menunjang aktivitas pemasaran ternak kuda akibat panjangnya rantai pemasaran, hambatan aksesibilitas ke pasar ternak, dan terbatasnya kelembagaan Koperasi Unit Desa (KUD) sehingga menimbulkan ekonomi biaya tinggi untuk sarana pengangkutan ternak kuda Sandelwood. Pada sisi yang lain penerapan teknologi pengolahan hasil lebih dominan hanya difokuskan kepada kacang mete, kacang sumba, dan kopi Sumba (bahan pangan nabati) sedangkan teknologi pengolahan Se'i (Daging asap), dendeng,maupun bakso (bahan pangan hewani) hanya dilakukan untuk komoditas ternak sapi, babi, kerbau, dan ayam.
Hukum kelembagaan merupakan dimensi yang memiliki atribut sensitif terbesar dalam pengembangan kuda Sandelwood di Kabupaten Sumba Barat Daya perlu mendapatkan perbaikan pada enam atribut sensitif untuk meningkatkan indeks keberlanjutan melalui penyediaan pusat pelatihan dan konsultasi pengembangan kuda Sandelwood. Hal tersebut merupakan sesuatu yang penting dalam upaya pengembangan kapasitas peternak khususnya dalam hal manajemen dan penerapan teknologi peternakan. Melalui ketersediaan pusat pelatihan dan konsultasi, secara tidak langsung akan membantu mengurangi hambatan ketersediaan tenaga penyuluh yang terbatas di setiap desamaupun frekuensi penyuluhan yang rendah di tingkat peternak karena mereka dapat dengan mudah untuk mengakses lembaga pelatihan dan konsultasi. Pada gilirannya ketersediaan pusat pelatihan dan konsultasi pengembangan kuda Sandelwood di Kabupaten Sumba Barat Daya dapat mendorong peningkatan alokasi kebijakan anggaran yang selama ini cenderung difokuskan pada komoditas selain kuda. Menarik minat masyarakat untuk tetap mengembangkan kuda Sandelwood sehingga pada gilirannya terjadi peningkatan populasi kuda Sandelwood, membuka peluang kerjasama pemasaran kuda Sandelwood, dan mengurangi terjadinya pencurian ternak kuda akibat tingginya kebutuhan yang tidak diimbangi oleh tersedianya populasi.

\section{Analisis Monte Carlo Pengembangan Kuda Sandelwood}

Analisis monte carlo digunakan untuk mengetahui besarnya faktor kesalahan (galat) yang diakibatkan oleh perbedaan penilaian responden terhadap atribut, kesalahan di dalam melakukan pemasukkan data, ataupun data yang kurang lengkap (Kavanagh, 2001). Hal tersebut secara teknis dilakukan dalam bentuk penilaian selisih indeks antara analisis Rap-horse (MDS) dan analisis Monte Carlo. Hasil perhitungan selisih indeks keberlanjutan pengembangan kuda Sandelwood di Kabupaten Sumba Barat Daya dapat dilihat pada Tabel 3 
Tabel 3. Selisih indeks keberlanjutan analisis Rap-horse (MDS) dengan Monte Carlo

\begin{tabular}{lccc}
\hline \multirow{2}{*}{ Dimensi Keberlanjutan } & \multicolumn{3}{c}{ Indeks Keberlanjutan (\%) } \\
\cline { 2 - 4 } & MDS & MC & Selisih \\
\hline Ekonomi & 33,08 & 33,14 & 0,06 \\
Teknologi - Infrastruktur & 39,40 & 39,41 & 0,01 \\
Hukum -Kelembagaan & 36,28 & 35,97 & 0,31 \\
\hline
\end{tabular}

Berdasarkan Tabel 3 diketahui bahwa hasil analisis Monte Carlo pengembangan kuda Sandelwood di Kabupaten Sumba Barat Daya pada taraf kepercayaan $95 \%$ menunjukkan hasil yang tidak banyak mengalami perbedaan (kurang dari 1) dibandingkan analisis Rap-horse (MDS). Indeks keberlanjutan dimensi ekonomi, teknologi-infrastruktur, dan hukumkelembagaan dengan selisih $0,01-0,31$ masih dibawah standar selisih yang ditetapkan. Hasil tersebut membuktikan bahwa kesalahan di dalam pembuatan skor untuk setiap atribut relatif kecil, keragaman pemberian skor akibat perbedaan opini relatif kecil, proses analisis data yang dilakukan secara berulang relatif memberikan hasil yang stabil, dan kesalahan dalam melakukan input data ataupun data yang hilang dapat dihindari.

Kecilnya selisih indeks keberlanjutan berdasarkan hasil analisis Monte Carlo juga membuktikan bahwa sistem yang dikaji memiliki tingkat kepercayaan yang tinggi dan metode Rap-horse sudah cukup baik dipergunakan sebagai salah satu instrument penilaian cepat terhadap pengembangan kuda Sandelwood. Kavanagh (2001) menyatakan bahwa selisih indeks keberlanjutan yang kurang dari 1 menunjukkan kecilnya pengaruh kesalahan dalam melakukan analisis.

\section{Keakuratan Analisis Rap-Horse Pengembangan Kuda Sandelwood}

Penilaian tingkat keakuratan di dalam menerapkan pendekatan analisis Rap-horse untuk evaluasi pengembangan kuda Sandelwood di Kabupaten Sumba Barat Daya ditunjukkan melalui nilai stress dan koefisien determinasi. Kavanagh (2001), Kavanagh dan Pitcher (2004), dan Hasdi (2015) menyatakan bahwa nilai stress yang lebih kecil dari 0,25 (25\%) menunjukkan bahwa hasil analisis sudah cukup baik, sedangkan nilai koefisien determinasi yang mendekati1(100\%) mengindikasikan atribut terpilih mampu menjelaskan mendekati 100 persen dari model yang dianalisis. Hasil analisis Rap-horse untuk nilai stress dan koefisien determinasi dapat dilihat pada Tabel 4.

Berdasarkan Tabel 4 diketahui bahwa semua atribut dimensi ekonomi, teknologiinfrastruktur, dan hukum-kelembagaan yang dikaji terhadap pengembangan kuda Sandelwood di Kabupaten Sumba Barat Daya memiliki hasil yang cukup akurat sehingga dapat dipertanggungjawabkan dan mampu mencerminkan keseluruhan atribut yang dianalisis (mendekati kondisi yang sebenarnya). Hal tersebut dapat diketahui dari nilai stress yang berkisar antara $14 \%$ $15 \%$ dan berada dibawah $25 \%$, serta nilai koefisien determinasi $\left(\mathrm{R}^{2}\right)$ sebesar 0,95 (95\%) yang mendekati nilai $1(100 \%)$.

Tabel 4. Hasil analisis Rap-Horse untuk nilai stres dan koefisien determinasi $\left(\mathrm{R}^{2}\right)$ pengembangan kuda Sandelwood di Kabupaten Sumba Barat Daya

\begin{tabular}{lccc}
\hline \multicolumn{1}{c}{ Parameter } & Ekonomi & Teknologi - Infrastruktur & Hukum -Kelembagaan \\
\hline Stres & 0,15 & 0,14 & 0,14 \\
Koefisien determinasi $\left(\mathrm{R}^{2}\right)$ & 0,95 & 0,95 & 0,95 \\
Iterasi & 2 & 2 & 2 \\
\hline
\end{tabular}




\section{KESIMPULAN}

Kuda Sandelwood yang dikembangkan di Kabupaten Sumba Barat Daya saat ini berada pada status kurang berkelanjutan dengan nilai indeks dimensi ekonomi $(33,08 \%)$, dimensi teknologiinfrastruktur $(39,40 \%)$, dan dimensi hukumkelembagaan $(36,28 \%)$. Terdapat 13 atribut yang sensitif berpengaruh terhadap pengembangan kuda Sandelwood dengan nilai Root Mean Square (RMS) tertinggi pada masing-masing dimensi adalah ketersediaan industri pengolahan hasil, pusat pelayanan kesehatan hewan (puskeswan), serta pusat pelatihan dan konsultasi kuda Sandelwood. Pemerintah Kabupaten Sumba Barat Daya perlu melakukan intervensi kebijakan politik dananggaran untuk mengoptimalkan pengembangan kuda Sandelwood yang berkelanjutan melalui perbaikan menyeluruh terhadap 4 atribut dimensi ekonomi, 3 atribut dimensi teknologi- infrastruktur, dan 6 atribut dimensi hukum- kelembagaan.

\section{UCAPAN TERIMA KASIH}

Penulis menyampaikan terimakasih kepada Direktorat Riset dan Pengabdian Masyarakat Dirjen Penguatan Riset dan Pengembangan Kemenristekdikti RI yang telah memfasilitasi pendanaan kegiatan melalui Penelitian Disertasi Doktor dengan nomor kontrak 07-055/SP2H/LTP2M/DRPM/IV/2017, tanggal 25 April 2017.

\section{DAFTAR PUSTAKA}

Anonimous. 2016. Populasi dan Pengeluaran Ternak di Kabupaten Sumba Barat Daya. Dinas Peternakan Kabupaten Sumba Barat Daya.

BPS Kabupaten Sumba BaratDaya. 2016. Kabupaten Sumba Barat Daya dalam Angka 2016.

Ditjennak Kementan. 2016. Statistik Peternakan dan Kesehatan Hewan Tahun2016.
Direktorat Jenderal Peternakan dan

Kesehatan Hewan. Kementerian Pertanian. Jakarta. https://drive.google.com/file/d/0B58J q7b22RQWallmb1NNZ091dGs/view. 29 Agustus 2018.

Direktorat Jenderal Peternakan. 2014. Keputusan Menteri Pertanian Republik Indonesia Nomor 426/Kpts/SR.120/3/2014 Tentang Penetapan Rumpun Kuda Sandel. http://bibit.ditjennak.pertanian.go.id/si tes/default/files/Kuda\%20Sandel.pdf. 22 Oktober 2015.

Erhun, M. O. 2015. A Sustainable Approach to Economic Development in Nigeria : A Legal Perspective. Journal of Economics and Sustainable Development. 6 (14) : 16.

Hasdi, A. S., A. M. Fuah, dan Salundik. 2015. Analisis Keberlanjutan Peternakan Sapi Perah di Wisata Agro Istana Susu Cibugary di Pondok Ranggon Cipayung Jakarta Timur. Jurnal Ilmu Produksi dan Teknologi Hasil Peternakan. 3 (3):157165.

Isyanto, A.Y., danY. A. Dehen. 2015. Sustainability Analysis of Beef Cattle Fattening in Ciamis Regency,West Java Province, Indonesia. Journal of Economics and Sustainable Development. 6 (20):148-154.

Kavanagh, P. 2001. Rapid Appraisal of Fisheries (Rapfish) Project. Rapfish Software Description (for Microsoft Excel). University of British. Columbia.

Kavanagh, $P$ and T. J. Pitcher. 2004. Implementing Microsoft Excel Software for Rapfish : A Technique for The Rapid Apraisal Fisheries Status. University of British. Columbia.

Olsen, S. L. 2006. Early Horse Domenstication on the Eurasian Steppe. Edition : Documenting domestication: new genetics and archaelogical paradigms. University of California Press. USA.

Pitcher, T. J., and D. Preikshot. 2001. RAPFISH: Rapid Appraisal Technique to 
Evaluate the Sustainability status of fisheries. Fisheries Research. 49 (3): 255270.

Randu, M. D. S. dan B. Hartono. 2018. Keragaan Pengembangan Kuda Sandelwood di Wilayah Pasola Kabupaten Sumba Barat Daya. Sains Peternakan. 16 (2): 54-62.

Sutanto, A., dan L. Hendraningsih. 2011. Analisis Keberlanjutan Usaha Sapi Perah di Kecamatan Ngantang Kabupaten Malang. Gamma. 7(1): 01-12.

Suyitman, S. H. Sutjahjo, dan A. Djulardi. 2012. Status Keberlanjutan Wilayah Berbasis Peternakan Sapi Potong Terpadu di
Kabupaten Lima Puluh Kota - Sumatera Barat. Jurnal Peternakan Indonesia. 14 (1): 318-336.

Syarifuddin, H. 2009. Indeks Keberlanjutan Integrasi Tanaman dengan Ternak (Crop Livestock System) di Kuamang Kuning. Jurnal Ilmiah Ilmu-ilmu Peternakan. 12(1): 41-49.

Vila, D., J. A. Leonard., and A. Beja-Pereira. 2006. Genetic Documentation of Horse and Donkey Domestication. Edition: Documenting Domestication: new genetics and archaeological paradigms. University of California Press. USA. 